\title{
Coatings applied on damp building substrates: performance and influence on moisture transport
}

Vânia Brito, Teresa Diaz Gonçalves, Paulina Faria

J. Coat. Technol. Res., 8 (4) 513-525, 2011

DOI 10.1007/s11998-010-9319-5

\begin{abstract}
Dampness is a common condition in old buildings and, accordingly, many paint systems specific for this type of building allow for application on walls with nonnegligible moisture content. In spite of that, performance evaluation of these paints is normally carried out using dry substrates or even on free paint films. This article presents research performed on 16 commercial paint systems: seven silicate, three silicone, three hydro-pliolite and two lime-based systems, as well as one common vinyl emulsion paint that served as reference. Each paint was applied and cured both on dry and on damp mortar substrates. The test specimens were subjected to water vapor permeability tests and evaporative drying tests. The following conclusions could be drawn: (i) the way paint systems influence the drying of the substrate, to which they were applied and where they cured, may vary significantly depending on the moisture content of that substrate; (ii) vapor permeability, measured with specimens applied and cured on dry substrate, may be an acceptable way of predicting a paint's influence on drying, provided that the paints are applied and cured on dry substrate or that their characteristics are not significantly affected by the moisture content of that substrate. Keywords Paint system, Old building, Damp
\end{abstract}

